International Journal of Linguistics, Literature and Translation

ISSN: 2617-0299 (Online); ISSN: 2708-0099 (Print)

DOI: $10.32996 / \mathrm{ijlt}$

Journal Homepage: www.al-kindipublisher.com/index.php/ijllt

\title{
Mobile-based Interactive Media in Remedial Reading Instruction
}

\author{
Alona Medalia Cadiz-Gabejan ${ }^{1} 8$ (D) $\varangle$, Eñego B. Tejas, Jr. ${ }^{2}$ (D) and Kristine Harion G. Lacanaria ${ }^{3}$ (D) \\ ${ }^{7}$ Assistant Professor II, Samar State University, Catbalogan City, Samar, Philippines \\ ${ }^{23}$ Student, Samar State University, Catbalogan City, Samar, Philippines \\ $\triangle$ Corresponding Author: Alona Medalia Cadiz-Gabejan, E-mail: alonamedalia.gabejan@ssu.edu.ph
}

\author{
ARTICLE INFORMATION \\ Received: April 02, 2021 \\ Accepted: May 10, 2021 \\ Volume: 4 \\ Issue: 5 \\ DOI: $10.32996 /$ ijllt.2021.4.5.9
}

\section{KEYWORDS}

Mobile-based, Interactive Media,

Reading, Remedial Reading

\section{ABSTRACT}

This study investigated if there would be a significant effect of using mobile-based interactive media on the word recognition and comprehension of Grade-7 students who underwent remedial reading classes because they were identified as non-readers or belonging to the frustration level of reading comprehension. It employed a standardized reading test in administering the pre-test and post-test among the students before and after utilizing the said interactive media, respectively. The test included word recognition (oral) and comprehension (written) tests to determine the reading ability of the students. The findings revealed that there was a significant difference between the pre-test and post-test scores of the students both for word recognition and comprehension. The use of mobile-based interactive media was found effective in enhancing the reading skills of students, even for those students who were already in Grade-7 and those who belonged to the Frustration Level of reading comprehension. The study recommended that a longer period of time could be allotted for remedial reading instructions while using mobile-based interactive media and that interviews could be used as a follow-up strategy in ascertaining the improvement of students' reading skills.

\section{Introduction}

Reading is essential for a child's success. Sometimes, the barriers faced by children with difficulty in reading restrain their desire to read and, without proper guidance, they never overcome them. Reading literacy is defined as "understanding, using, and reflecting on written texts in order to achieve one's goals, to develop one's knowledge and potential, and to participate in society" (Therrien, 2004). There are various factors that cause the increasing number of non-readers, particularly in public schools and one of them is the inappropriateness of the materials or techniques used by teachers.

In the Department of Education (DepEd) in the Philippines, particularly in Samar National School (SNS), Catbalogan City, 250 of the enrollees in the school year 2018-2019 for Grade Seven were identified as non-readers. As observed after the diagnostic reading test upon enrolling, these students could not recognize letters and sounds of each word. They were, then, obliged to attend the school's remedial classes or the Remedial Reading Instruction program of Samar National School (SNS). They focused on improving the students' reading skills that were not thoroughly given attention before entering the secondary level. However, the instructional materials they were using were traditional, like the use of flashcards, charts, textbooks, worksheets, etc.

The term remedial refers to correcting or improving deficient skills in a specific subject (Sudhakar, 2018). Thus, remedial reading is a change in instruction that helps remedy a weakness in the area of reading. It is an instruction in reading which aims at increasing speed and comprehension by correcting poor reading habits. Teachers may experience a need for a special reading program as a result of meeting with failure in instructing certain students by conventional methods. Administrators may feel a need for a remedial reading program after studying comprehensive plans to improve classroom instruction in reading.

\section{K C AL-KINDI CENTER \\ $\mathbf{R}$ D FOR RESEARCH AND DEVELOPMENT}

Your gateway to world-class research

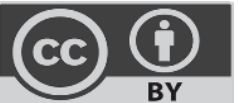

Published by Al-Kindi Center for Research and Development, London, United Kingdom. Copyright (c) the author(s). This open access article is distributed under a Creative Commons Attribution (CC-BY) 4.0 license 
The researchers conducted this study among the non-readers of Samar National School under the reading remediation class to test if there would be a significant difference as to how these students will learn how to read with the intervention of the adopted mobile-based interactive media in the instruction.

Interactive media is a method of communication in which the program's outputs depend on the user's inputs, and the user's inputs, in turn, affect the program's outputs. Interactivity is defined as the degree to which two or more communication parties (human or computer) act on each other in an interrelated manner (Koolstra \& Bos, 2009). A structured, multisensory approach helps children to acquire knowledge by using their senses simultaneously - hear it, see it, and write it. This strategy seeks to actively stimulate all senses to trigger the interest for learning (Vickery, Reynolds, \& Cochran, 1987). One alternative way to teach reading is by using android-based interactive media. It can help the learning system while playing in the classroom, in the family, and in society which must be under the control and supervision of an adult (Bhaskar, 2013). The use of multimedia technologies is prepared as good as possible and can influence the reading process from teaching-learning (Neuman, 2010).

Hence, this study determined if there is a significant effect in using Mobile-based Interactive Media in Remedial Reading Instruction among grade seven non-reader students in SNS. Specifically, the study sought to answer the following questions:

1. What is the pre-test scores of the student-respondents in terms of:

1.1 word recognition; and

1.2 comprehension?

2. What is the post-test scores of the student-respondents in terms of:

2.1 word recognition; and

2.2 comprehension?

3. Is there a significant difference in Remedial Instruction between students with interactive media and those who do not have in:

3.1 word recognition; and

3.2 comprehension?

\subsection{Null Hypothesis}

There is no significant difference between the pre-test and post-test scores of students for word recognition and comprehension before and after using the mobile-based interactive media, respectively, in their Remedial Reading classes.

\section{Literature review}

This study was anchored on the herein theories and was guided by the succeeding related studies and literature.

In Bloomfield's Theory of Reading, it purports that for a child to learn how to read, he/she must be acquainted with the letters at the very start, before the reading begins." Children would be "ready" to read when they had developed certain prerequisite skills such as familiarizing the alphabet letters first. Then, they would be evaluated by readiness testing (Gesell, 1925).

Multi-Sensory Approach (Anderson \& Krathwohl, 2001) asserts that "the more senses involved, the better the learning". This theory states that the brain achieves learning more easily when several senses are stimulated in parallel. Think about the five (5) senses: sight, sound, touch, taste, and smell. Each of these senses accesses information in a unique way, and the brain coordinates the input from all the senses to learn. With more senses engaged in a lesson, the learner is more likely to remember the information. "Learning to read and write is a complex, multifaceted process that requires a wide variety of instructional approaches" (Neuman et al., 2000).

The literature provides a rich contextual foundation upon which to study the use of interactive media among Grade- 7 nonreaders.

A variety of reading programs targeted specific decoding skills sets and directed instruction of vocabulary. The National Reading Panel (2000) identified three (3) key elements of effective reading instruction: alphabetic (phonemic awareness and phonics), fluency, and comprehension (vocabulary, text comprehension, and comprehension strategies). Phonological awareness, or an understanding of the sounds of language, can be quantified through tasks such as rhyming, blending sounds, and word-sound games that assess the ability to manipulate phonemes and syllables (Noble et al., 2005). The use of technology is such that interactive media are offered for their great potential. Interactive media programs considered a supplement to quality instruction. To promote transfer, the concepts in these programs should be reinforced during instruction, for example, adopting the terms of the program uses and revisiting sample words. Programs that focus centrally on print and language concepts and programs that include progress monitoring features are best. According to the agency of policy regarding media and communications in the United States or the policy statement of the American Academy of Pediatrics (AAP), Council on Communications and Media (2011) describes the interactive media with high quality that can provide benefits for children in improving social skills, language, and reading readiness in school. A study found that these basic interactive books that simply 
read a story aloud and highlighted words and phrases as they were spoken were beneficial for children who had different styles for learning, and interactive media helped children with visual skills.

Interactive media make students involved in learning. In reading, students' involvement greatly affects their learning best. Many studies and investigations to the use of technology, including multimedia environments, emphasized student's interest, motivation, and engagement (Reinking \& Bradley, 2011). These elements are vital for those students who are reluctant or struggling readers. The ability to customize viewing and interaction contributes to student engagement and motivation, but they lament the lack of choice in most technology-based reading research studies. In a study conducted by Strangman and Dalton (2005), they stressed out that interactive media is vital to students' changing feelings about reading itself.

From the study of Wise, Ring, and Olson (2004), a decade-long investigation of computer-based remediation of phonemic awareness have been examined in Colorado schools. Their respondents were elementary students. They have developed and tested the two (2) programs to facilitate and supplement reading instruction as they served. These were the Accurate Reading in Context (ARC). Here, students spent 22 hours reading stories with speech recognition and Phonological Analysis (PA), which had an explicit instruction of speech articulation and animated storybooks and other word-level analyses. These facilitated supplemental interventions required a trained teacher to facilitate and monitor young students' interaction with the computerbased program and deliver small-group instruction supportive of transfer. The study included matched control groups. Students who participated in the program demonstrated significant gains in phonemic awareness, decoding, and word reading which were maintained at a 1- and 2-year follow-up (Wise et al., 2000). These programs had similar results, suggesting that increased facilitated time spent in reading-not the specific type of training-was key. They suggested that additional time and transfer activities would increase performance and retention of gains.

On the other hand, Lewandowski, Begeny, and Rogers (2006) found that 66 third-grade students' word recognition, reading speed, and accuracy scores improved similarly the following practice with a very simple (no graphics or animation) computerbased reading program and work with a live tutor. Students' scores in a no-help condition did not improve. This study reinforced an earlier study in which Lewandowski and Montali (1996) showed that struggling elementary readers could perform and average achieving peers on word recognition and accuracy tests when there was an audio plus visual input with computer-based practice.

In Ertem (2010) study, the comparison and analysis of student comprehension using all three (3) media effects of digital texts on student comprehension were shown. Data showed that there was a great increase in reading compression when students were engaged in digital texts and were incorporated with animations. Digital texts without animations were resulted being the second-highest scores in comprehension, while the traditional texts had the lowest scores within reading compression. Therefore, the data collected found that electronic storybooks can improve and support the reading comprehension of struggling readers. Digital texts incorporate features such as animations and reading options result in improved reading comprehension skills for struggling readers.

Further, according to Ertem (2010), through the analysis of student retellings, animations within digital texts resulted in understanding the underlying theme of the text, plot, and solutions within the story better than traditional text illustrations. Students using electronic texts showed signs of higher-level thinking and reached a more advanced level of comprehension. However, according to him, no date would clearly support the effects of having digital texts or traditional text to increase the motivation of the students to read.

Linebarger, Kosanic, Greenwood, and Doku (2004) studied the impact of the program on 164 kindergarten and first-grade students. These students were at risk, at moderate risk, or not at risk for reading failure. Over the course of the investigation, all children's print concepts and reading skills were developed. The children who had already mastered some print concepts - the moderately at-risk group - demonstrated the most growth. Results were successful. Authors reasoned that the content matched these students' emerging understanding of literacy concepts but may have been too high or too low for the other student groups.

A study in the Philippines entitled, "Effectiveness of Remedial Reading Classes Using Special Methods to Non-readers in Filipino of Grade One Pupils of General Maximo Hizon Elementary School," brought a very significant result to students that it helped increase the readers' reading skill among Grade One pupils. Grade One teachers observed from those several methods, and the Hegge-Kirk-Kirk Method prevailed as the most dominant than their own modified style. Their study strongly supported the importance of phonics to reading success. 
The above-mentioned studies have the same problems in Samar National School, the problem raised in this study. However, there was a big gap in this study compared to those students who were identified as non-readers because, in this study, the respondents were not in kindergarten or elementary, but were already first year high school and normal students who did not have any disabilities nor in late development problem.

Many parents and educators held negative attitudes toward interactive devices for learning purposes compared to the perceived benefits of 'real-world' learning opportunities (Wooldridge, 2016). In the reviews of Radesky et al. (2015), limited researches on the impact of interactive media used on children were found and they suggested that interactive media could be useful for teaching concrete knowledge. However, they posited that if skills such as self-regulation and empathy are perhaps best learned through interactions with peers and caregivers in naturalistic environments, in contrast to that, interactive media are very helpful as medium of instruction for they create the possibility of display and response dialogue.

\section{Methodology}

This section consists of descriptions of the research design, instrumentation, validation of the instrument, and data gathering procedure.

\subsection{Research design}

This study is quantitative experimental research where researchers conducted pre-test and post-test to determine the results before and after introducing the adopted interactive media applications in the remedial instructions among Grade-7 non-readers of Samar National School.

\subsection{Instrumentation}

The researchers used interactive media, particularly mobile-based interactive media applications, wherein students had an actual experience of having an active interaction with the provided mobile application. It had a guide in which it was given from a spoken instruction and directions that they needed to follow. The researchers introduced the mobile applications to the students and taught them how to use them. After giving instructions to the student-respondents, the researchers facilitated them while they were learning by themselves with the aid of the mobile applications.

\subsection{Validation of the instrument}

Since the instrument used in this study was an adopted mobile-based interactive media application, it underwent validation process. It was reviewed by the researchers' consultative adviser and by the remedial reading specialists in Samar National School (SNS).

The instruments used in conducting the pre-test and the post-test were the same instruments used by the remedial reading advisers in SNS in their administration of diagnostic test in their school among Grade-7 students.

\subsection{Data gathering procedure}

Through the school head, the researchers asked the advisers of the remedial classes to get the list of the identified non-readers of the school.

Using the school's standardized diagnostic test tool, the researchers conducted a pre-test to the students under the remedial instruction before introducing the interactive mobile application. This was the same material used to diagnose students who were enrolled in the remedial class. The test included word recognition (oral) and comprehension (written) tests to determine the students' reading ability.

After conducting the pre-test and after having been able to determine the ten (10) students who belonged to the frustration level of reading - who could recognize words and sounds but struggled to read and could not comprehend - the researchers then introduced the mobile-based interactive media, the researchers served as facilitators in using the interactive media in the remedial instruction.

The hour's length was 45-60 minutes for each meeting. The same tools - the interactive media - were used for all the students in the reading remediation. Students had interactive learning with the interactive mobile applications for BASIC CVC WORDS TO HELP KIDS READ and ABC Words. They were exposed to these and had interaction with the moving images and graphics.

After the respondents had taken the post-test, their papers were checked, tallied, and handed to a statistician for data analysis.

\subsection{Statistical treatment of data}

Mean. This statistical measure was used to determine the quantitative reading level of the student-respondents. 
Standard Deviation. This statistical measure was utilized in describing the extent to which the reading level varied among themselves.

T-test. This statistical tool was used to test the difference of comprehension of student-respondents before and after they utilized the mobile-based interactive media while they were in their remedial reading instruction.

\section{Results}

This section presents the findings, analysis, and interpretation of data based on the specific questions presented in this investigation. For clarity in the presentation of data, appropriate tables were used.

\subsection{Word recognition and comprehension of the student-respondents (pre-test)}

This section discusses the data pertaining to the word recognition and comprehension (pre-test) of the student-respondents who were involved in this study.

Word Recognition (Pre-test). Table 1 shows the word recognition (pretest) of the student-respondents. The highest number of words recognized by the student-respondents was 38 words in a minute, while the lowest was 26 words. Six of the studentrespondents got 30, 34 and 38 words. The average of the student-respondents posted at 31.90 words with a standard deviation of 4.07 words.

Table 1: Word Recognition Distribution of the Student-Respondents (Pre-test)

\begin{tabular}{ccc}
\hline $\begin{array}{c}\text { Word Recognition } \\
\text { (Pretest) }\end{array}$ & Frequency & Percentage \\
\hline 26 & 1 & 10.0 \\
28 & 1 & 10.0 \\
29 & 1 & 10.0 \\
30 & 2 & 20.0 \\
32 & 1 & 10.0 \\
34 & 2 & 20.0 \\
38 & 2 & 20.0 \\
Total & 10 & 100.0 \\
\hline Mean & 31.90 & \\
\hline SD & 4.07 & \\
\hline
\end{tabular}

Comprehension (Pre-test). Table 2 shows the information about the comprehension (pre-test) of the student-respondents. Ten or 100 percent of the student-respondents was at Frustration Level. The average of the student-respondents posted .48 percent with a standard deviation of .08 percent.

Table 2: Comprehension Distribution of the Student-Respondents (Pre-test)

\begin{tabular}{ccc}
\hline $\begin{array}{c}\text { Comprehension (Pre- } \\
\text { test) }\end{array}$ & Frequency & Percentage \\
\hline Independent Level & 0 & 0.0 \\
Instructional Level & 0 & 0.0 \\
Frustration Level & 10 & 100.0 \\
Non-readers & 0 & 0.0 \\
\hline Total & 10 & 100.0 \\
\hline Mean & 0.48 & \\
\hline SD & 0.08 & \\
\hline
\end{tabular}

Legend:
Levels

Independent Level

\section{Word Recognition}

.98 or $98 \%$
Comprehension

.80 or $80 \%$ 


$$
\text { Instructional Level }
$$

Frustration Level

Non-readers
.95 or $95 \%$

.94 or $94 \%$

0
.75 or $75 \%$

below .75 or $75 \%$

0

\subsection{Word recognition and comprehension of the student-respondents (post-test)}

This section discusses the data pertaining to the word recognition and comprehension (post-test) of the student-respondents who were involved in this study.

\begin{tabular}{ccc} 
Table 3: Word Recognition Distribution of the Student-Respondents (Posttest) \\
\hline $\begin{array}{c}\text { Word Recognition } \\
\text { (Posttest) }\end{array}$ & Frequency & Percentage \\
\hline 30 & 2 & 20.0 \\
31 & 1 & 10.0 \\
32 & 1 & 10.0 \\
34 & 1 & 10.0 \\
35 & 1 & 10.0 \\
36 & 1 & 10.0 \\
38 & 1 & 10.0 \\
39 & 1 & 10.0 \\
42 & 1 & 10.0 \\
\hline Total & 10 & 100.0 \\
\hline Mean & 34.70 & \\
\hline SD & 4.08 & \\
\hline
\end{tabular}

Word Recognition (Post-test). Table 3 shows the word recognition (post-test) of the student-respondents. The highest number of words recognize by the student-respondents was 42 words in a minute, while the lowest was 30 words. Two of the studentrespondents got 30 words. The average of the student-respondents posted at 34.70 words with a standard deviation of 4.08 words.

Comprehension (Post-test). Table 4 shows the information about the comprehension (post-test) of the student-respondents. Ten or 100 percent of the student-respondents was at Frustration Level. The average of the student-respondents posted .52 percent with a standard deviation of .08 percent.

Table 4: Comprehension Distribution of the Student-Respondents (Post-test)

\begin{tabular}{ccc}
\hline $\begin{array}{c}\text { Comprehension (Post- } \\
\text { test) }\end{array}$ & Frequency & Percentage \\
\hline $\begin{array}{c}\text { Independent Level } \\
\text { Instructional Level }\end{array}$ & 0 & 0.0 \\
Frustration Level & 0 & 0.0 \\
Non-readers & 10 & 100.0 \\
\hline Total & 0 & 0.0 \\
\hline Mean & 10 & 100.0 \\
\hline SD & 0.52 & \\
\hline
\end{tabular}

\section{Legend:

Levels

Independent Level

Instructional Level
Word Recognition

.98 or $98 \%$

.95 or $95 \%$

\section{Comprehension}

.80 or $80 \%$

.75 or $75 \%$ 


\subsection{Difference of word recognition between students' pre-test and post-test}

Table 5 reflects the difference in student-respondents' word recognition skills before and after they utilized the mobile-based interactive media while they were in their remedial reading instruction.

Word Recognition of the Students with Interactive Media. Since the computed p-value was less than 0.05 level (2-tailed), there was enough evidence to reject the null hypothesis. Therefore, the word recognition of the student-respondents when they already used the mobile-based interactive media had a significant difference from the circumstance when they were not yet using the said interactive media in their remedial reading instruction.

Table 5: Difference of Word Recognition between students Pre-test and Post-test

\begin{tabular}{cccccc}
\hline & Mean Difference & $\mathbf{t}$ & Df & $\begin{array}{c}\text { Sig. (2- } \\
\text { tailed) }\end{array}$ & Decision \\
\hline $\begin{array}{c}\text { Students w/ IM - Students } \\
\text { w/out IM }\end{array}$ & 2.8 & 2.635 & 9 & 0.027 & Reject $\mathrm{H}_{\circ}$ \\
\hline
\end{tabular}

\subsection{Difference of comprehension between the students' pre-test and post-test}

Table 6 reflects the difference in student-respondents' comprehension before and after they utilized the mobile-based interactive media while they were in their remedial reading instruction.

Table 6: Difference of Comprehension between Students Pre-test and Post-test

\begin{tabular}{cccccc}
\hline & Mean Difference & T & Df & $\begin{array}{c}\text { Sig. (2- } \\
\text { tailed) }\end{array}$ & Decision \\
\hline $\begin{array}{c}\text { Students w/ IM - } \\
\text { Students w/out IM }\end{array}$ & 2.4 & 2.714 & 9 & 0.024 & Reject Ho \\
\hline
\end{tabular}

Comprehension of Students After Using the Mobile-based Interactive Media. Since the computed p-value was less than the 0.05 level (2-tailed), there was enough evidence to reject null hypothesis. Therefore, the comprehension of the studentrespondents when they already used the mobile-based interactive media had a significant difference from the circumstance when they were not yet using the said interactive media in their remedial reading instruction. This means that the use of interactive media was effective to students for to learn how to read.

\section{Conclusions}

Some conclusions are drawn based on the findings of the study. First, there was a significant difference between the scores of the students for word recognition in the pre-test and their scores in the post-test. Second, there was also a significant difference between the scores of the students for comprehension test in the pre-test and post-test. Hence, the researchers had enough evidence to reject the null hypothesis. This means that, indeed, the use of mobile-based interactive media was effective in enhancing the reading skills of students, even for those students who were already in Grade-7 and those who belonged to the Frustration Level of reading comprehension. Along with the findings and conclusions, the researchers recommended that a longer period of time could be allotted for remedial reading instructions while using mobile-based interactive media. Moreover, interviews could be used as a follow-up strategy in verifying the results obtained from the tests. Future researchers could undertake further research on Interactive Media to validate the results of the study. 


\section{References}

[1] Anderson, L. W., and Krathwohl, D. R. (2001). A Taxonomy for Learning, Teaching, and Assessing: A Revision of Bloom's Taxonomy of Educational Objectives. https://www.uky.edu/ rsand1/china2018/texts/Anderson-Krathwohl\%20\%20A\%20taxonomy\%20for\%20learning\%20teaching\%20and\%20assessing.pdf

[2] Bhaskar, M. (2013). The Content Machine: Towards a Theory of Publishing from the Printing Press to the Digital Network. New York: Anthem Press. https://quod.lib.umich.edu/i/jep/3336451.0017.210?view=text;rgn=main

[3] Ertem, I. S. (2010). Effect of Electronic Storybooks on Struggling Fourth-Graders' Reading Comprehension. Turkish Online Journal of Educational Technology - TOJET, v9 n4 p140-155. https://files.eric.ed.gov/fulltext/EJ908080.pdf

[4] Gesell, A. (1925). Pre-School Development and Education. SAGE Journals. https://journals.sagepub.com/doi/abs/10.1177/000271622512100122

[5] Koolstra, C., et. al., (2009). The Development of an Instrument to Determine Different Levels of Interactivity. Retrieved online from http://journals.sagepub.com.

[6] Lewandowski, L., Begeny, J., \& Rogers, C. (2006). Word-recognition training: Computer versus tutor. Reading \& Writing Quarterly: Overcoming Learning Difficulties, 22(4), 395-410. https://doi.org/10.1080/10573560500455786

[7] Lewandowski, L. \& Montali, J. (1996). Bimodal Reading: Benefits of a Talking Computer for Average and Less Skilled Readers. Journal of Learning Disabilities. https://doi.org/10.1177/002221949602900305

[8] Neuman, S., and Marulis, L. M. (2010). The Effects of Vocabulary Intervention on Young Children's Word Learning A Meta-Analysis. Review of Educational Research 80(3):300-335. DOI: 10.3102/0034654310377087

[9] Neuman, S., Copple, C., \& Bredekamp, S. (2000). Learning to Read and Write: Developmentally Appropriate Practices for Young Children. National Association for the Education of Young Children. https://psycnet.apa.org/record/2001-14034-000

[10] Noble, K. G. et al. (2005). Neurocognitive correlates of socioeconomic status in kindergarten children. Developmental Science, Volume 8 , Issue 1 p. 74-87. https://onlinelibrary.wiley.com/doi/abs/10.1111/j.1467-7687.2005.00394.x

[11] Reinking, D. \& Bradley, B. (201). Enhancing research and practice in early childhood through formative and design experiments. Early Child Development and Care 181(3):305-319. DOI: 10.1080/03004430903357894

[12] Strangman, N., \& Dalton, B. (2005). Technology for struggling readers: A review of the research. In D. Edyburn, K. Higgins, \& R. Boone (Eds.), The handbook of special education technology research and practice (pp. 545-569). Whitefish Bay, Wl: Knowledge by Design.

[13] Sudhakar, J. (2018). Remedial Classes Enables the Child to Gain Positive Impact by Filling His Cognitive Gaps! https://www.linkedin.com/pulse/remedial-classes-enables-child-gain-positive-impact-filling-sudhakar

[14] Therrien, W. J. (2004). Fluency and Comprehension Gains as a Result of Repeated Reading: A Meta-Analysis. SAGE Journals. https://doi.org/10.1177/07419325040250040801

[15] Vickery, K. S., Reynolds, V. A., and Cochran, S. W. (1987). Multisensory Teaching Approach for Reading, Spelling, and Handwriting: OrtonGillingham based Curriculum in Public School Setting, p. 89-90. https://pubmed.ncbi.nlm.nih.gov/24234994/

[16] Wise, B., Ring, J., \& Olson, R. K. (2000). Individual Differences in Gains from Computer-Assisted Remedial Reading. Journal of Experimental Child Psychology 77(3):197-235. DOI: 10.1006/jecp.1999.2559 